\title{
Electric Vehicle Storage Management in Operating Reserve Auctions
}

\author{
Micha Kahlen \\ Erasmus University Rotterdam \\ kahlen@rsm.nl
}

\author{
Wolfgang Ketter \\ Erasmus University Rotterdam \\ wketter@rsm.nl
}

\author{
Alok Gupta \\ University of Minnesota \\ alok@umn.edu
}

\begin{abstract}
Carsharing operators, which rent out electric vehicles for minutes or hours, lose money on idle vehicles. We develop a model that allows carsharing operators to offer the storage of these vehicles on operating reserve markets (market for quickly rampable back-up power sources that replace for instance failing power plants). We consider it a dispatch and pricing problem with the tradeoff between the payoffs of offering vehicles for rental and selling their storage. This is a problem of stochastic nature taking into account that people can rent electric vehicles at any time. To evaluate our model we tracked the location and status of 350 electric vehicles from the carsharing company Car2Go and simulated the dispatch in the Dutch market. This market needs to be redesigned for optimal use of storage. We make recommendations for the market redesign and show that carsharing operators can make substantial additional profits in operating reserve markets.
\end{abstract}

\section{Introduction}

Carsharing operators, which rent electric vehicles for minutes or hours, lose money on idle vehicles. We propose a new business model with which they can use the storage of these idle electric vehicles (EVs) on operating reserve markets to create higher profits. This market is a smart market [11, 6, 3], which alleviates power imbalances with a dynamic auction based mechanism. In this market power sources are traded that can serve as an instant back-up when another power-source fails (for example when a power plant has a defect), or to dump excess electricity (from for example too much wind). Carsharing operators can participate in this market as a Virtual Power Plant (VPP). They pool together several electric vehicles from different locations to act as if they were one power source that can provide and take back electricity according to the market's need $(13,2)$.

We design offers (bids/asks) with respect to price and quantity to participate in the tender for operating reserves. These offers, which relate to both charging and discharging, are determined by taking into account the expected revenues that could be earned by making an electric vehicle available for rent at specific points in time. That has the effect that whenever the market accepts (settles) these offers, the carsharing company always earns more with them than what they would have earned by renting alone.

To test the effectiveness of our strategy we test it in a simulation, which we calibrate with real data as suggested by $[9,10]$. To validate our finding we need data on carsharing electric vehicle transactions and their battery status over time and data on the operating reserve market tender. We track the location and battery status of 350 electric vehicles of their Car2Go fleet (www.car2go.com) in real-time over a 14 month period. The tender data on the operating reserve auction is accessible through the Dutch transmission system operator Tennet.

In our analysis we show that carsharing companies can increase their profits by participating in operating reserve markets with their electric vehicles as virtual power plants. However, we find that under current prices in the Netherlands it is not profitable to use vehicle-2-grid (discharging the electric vehicles to provide electricity to the grid). The increased revenues come from charging the electric vehicles with excess electricity from the grid. For example when wind parks produce too much electricity for the grid to handle, they pay the electric vehicles to absorb the excess electricity. Therefore the carsharing operator saves money on charging the electric vehicles in the first place, plus the payment to take on excess electricity. This means that the carsharing operator needs to be more flexible over time on when to charge the electric vehicles but we show that this does not significantly affect rental operations.

The strategy that our model prescribes is sustainable as it helps to balance volatile renewable energy sources. As the demand for renewable energy is increasing in many parts of the world there will also be a higher need for operating reserve power, which we can partially deliver with electric vehicles. With an increased demand also vehicle-2-grid may be economically worthwhile. With the strategy that our model prescribes, we create an incentive for people and business to behave sustainably, which is "an 
opportunity to create shared value -- that is, a meaningful benefit for society that is also valuable to the business" [13].

The paper is structured as follows. First, we will describe the background of our work on how the operating reserve market works and present the literature that our model builds on. Second, we explain the details of our model. After we have outlined the model we go in on the data and will illustrate how we use the data to evaluate the model. Next, we will analyze our findings. Finally we will conclude our work including an outlook on future research.

\section{Background and related work}

In this section we will first provide a background of the market functioning of operating reserves. We will also make recommendations on how this market should be adapted in the future to be suitable for storage. Afterwards, we will describe the literature on the field of smart charging and vehicle-2-grid with electric vehicles, what has been done already, and how our research extends what has been done so far.

\subsection{Operating reserve market design}

The operating reserve market is an auction which is usually administered by the transmission system operator. This market guarantees to keep the grid in balance at all times by avoiding over or underproduction of electricity which would result in blackouts. To participate in this market participating parties have to show that their resources can ramp up to full production capacity within 30 seconds so that it can react quickly when there is over or under production. The tender for this auction is done on a weekly basis where parties can submit their offers for the upcoming week. They can submit asks if they want to sell electricity and they can submit bids if they want to buy electricity. Once their bids and asks are submitted the units need to be available (reserved) at all times for which they are compensated with a capacity fee. The market operator decides based on demand and supply whether to the offered asks or bids are executed. The executed bids and asks are paid the respective price that they submitted with their offers and are settled in merit order (cheapest resources are used first). The clearing mechanism functions as a "pay-as-bid" auction. Figure 1 illustrates the market clearing mechanism. In this example the market needs to get rid of clearing quantity $\mathrm{Q}^{*}=1,100 \mathrm{MWh}$. All participating bids are sorted in merit order so that bids $1,5,16$, and 3 (partially) are settled. This means that they have to use the quantity specified in their bids and

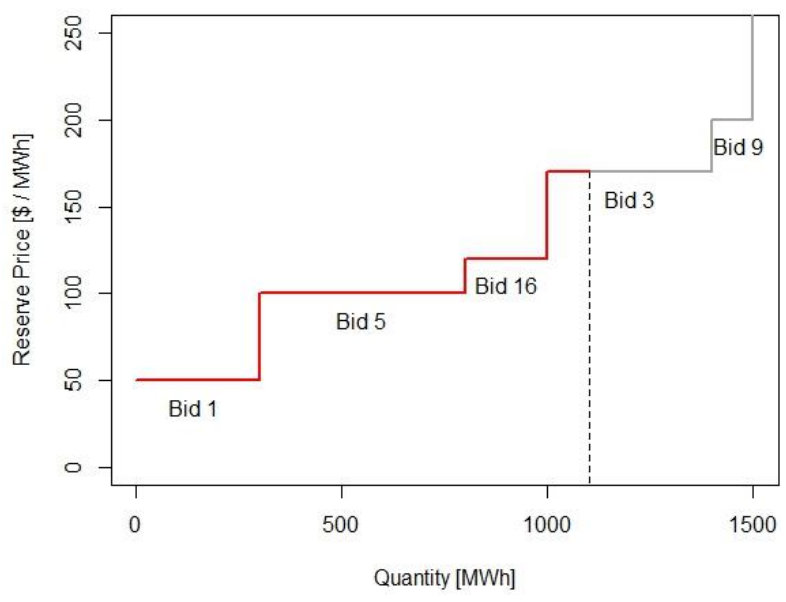

Figure 1. Multi-unit pay-as-bid auction. All bids to the left of $Q^{*}$ (bid 1, 5, 16, and partially 3 ) are cleared at their respective prices $(50,100,120$, and $175 \$ / \mathrm{MWh})$.

are paid their submitted price. Note that there is a 1 MWh minimum lot size on this market, which we will disregard as in reality one would just need larger fleets.

8.1.1. Recommended changes to market design. Current regulations reflect a market that is characterized by fossil fuel based resources. In theoretically extreme cases it could ask participating parties to deliver electricity for the whole week. This would require very large batteries that would never be used to their full capacity. We therefore recommend and will proceed as if the market would allow bids for time intervals with 15 minute increments. This allows also storage to participate in this market and is in line with recommendations by a study commissioned by a consortium of Dutch and German transmission system operators [1].

\subsection{Operating reserves from electric vehicles}

Previous research has already studied smart charging. In smart charging electric vehicle owners get financial incentives to shift charging times to less congested hours. Fridgen et al. [5] and Valogianni et al. [19] have shown that this reduces peaks in the grid. Other studies have also studied the vehicle-2-grid concept. Its efficiency has been validated by an information system in a micro grid context [4]. Given the departure times of EVs parked at public charging stations other authors [8] show a reduction in the monthly energy bill of $24.8 \%$. A similar setting was also researched by Vytelingum et al. [20] who find a utility bill reduction of $14 \%$ for households that use a 
battery exposed to dynamic pricing at the energy wholesale market. Other studies that consider electric vehicles estimate the annual profits per vehicle to be \$10-120 [12], \$176-203 [17], and \$415-826 [15]. However, none of these studies use data from electric vehicles or take uncertainty about driving behavior into account. Tomic and Kempton [18] show that vehicle-2grid can be profitable with a real fleet of hybrid electric vehicles. However, this study assumes that the time and distance of the trips made with these electric vehicles are known perfectly in advance. A shortcoming of the existing studies is that they assume trips are assumed to be known in advance. This does not always hold in reality and is problematic when an electric vehicle is committed to either charge or to do vehicle-2-grid at the same time as someone needs to drive it. We will describe our model, which builds on [7] in the next section, does not make strong assumptions on driving patterns and is therefore applicable in practice in contrast to previous studies.

\section{Model Description}

We submit offers to the operating reserve auction that reflect the underlying valuations of the carsharing company. These offers include the (opportunity) cost for the operator to commit electric vehicles to the market. The model makes decisions about how much storage should be offered $(\mathrm{Q})$ and at what price $(\mathrm{P})$. The quantity and price can be different per 15 minute time interval to reflect the different expected profits from rental transactions which changes over the course of a day/week. Our model determines quantities and prices for both discharging and charging for each time interval and submits them to the market. Based on the merit order the market decides whether and to what degree he wants to make use of these offers. If the market decides it wants to use these offers for a certain 15 minute time interval we need to provide and absorb the requested quantity up to the maximum of the full offered quantity Q. For that purpose we have to allocate specific electric vehicles. If these electric vehicles are available everything is fine. However, if we observe in the data that during this process a customer rented one of those electric vehicles, we can create a virtual power plant. A virtual power plant means that it does not matter to the market which electric vehicle to deploy as long as we deliver the committed quantity. That is if another idle electric vehicle is available and connected to the grid we can replace the rented one with the other idle electric vehicle and still live up to our commitment and rent out an electric vehicle. We are dealing with asymmetric payoffs in this case. While renting out an electric vehicle earns around $\$ 15$ of profits on average, storage only earns $\$ 0.05$ on average. But under no circumstances can we go back on our commitment to the operating reserve market because this would lead to high penalties (ACM Framework Agreement Art. 7, Par. 3). We therefore have to adapt our models to reflect these asymmetric payoffs. Whenever we do commit units to the operating reserve market we need to be very certain that these electric vehicles will not be rented out. Therefore we apply a sampling method that is proportional to the payoffs more likely to select training cases where electric vehicles are rented. In other words the proportion of rental:NoRental cases in the training data set is sampled 300:1 (\$15/\$0.05). In general we apply a two month training data set to learn about the availability of vehicles and the prices we should charge and evaluate it over one test week (the tender period). We chose two month because we had 14 month of data and could then test our strategy over a whole year. In the following we will describe in more detail how exactly we determine the offer quantities (Q) and then we will describe how we will price (P) these quantities.

\subsection{Offer quantity composition}

We need to know how much idle capacity for both charging and discharging the entire fleet has at any future time. We consider only electric vehicles parked at charging stations for this. This is the quantity that we want to submit to the operating reserve market. We use the machine learning algorithms neural networks, random forest, and support vector machines to predict the storage available for charging $\left(Q^{\text {charge }}\right)$ and the storage available to discharge $\left(\mathrm{Q}^{\text {discharge }}\right)$. The quantity needs to be known up to one week in advance already because that is when the tender closes for the following week. The quantities are discounted by a charging and discharging efficiency of $96 \%$ and $97.4 \%$ respectively [16]. The underlying logic and therefore model is the same for charging and discharging, as it depends on the day of the week, the hour of the day, and the lagged dependent variable (based on the availability in the weeks before at the same day and time):

$$
\begin{gathered}
y_{t}=\beta_{0}+\beta_{1} * \operatorname{day}_{\text {week }}(\mathrm{t}) \\
+\beta_{2} * \text { hour }_{\text {day }}(\mathrm{t}) \\
+\beta_{3} * y_{t-1 . .9}
\end{gathered}
$$

where y can either be $\mathrm{Q}^{\text {discharge }}$ or $\mathrm{Q}^{\text {charge }}$ depending on which variable one wants to forecast; the underlying model is the same.

A random forest model with 2 randomly preselected variables, 1000 randomized trees, and a 
minimum sum of weights for splitting of 5 was the method with the highest accuracy for both $\mathrm{Q}^{\text {charge }}$ and $\mathrm{Q}^{\text {discharge }}$.

\subsection{Offer price composition}

Besides the offer quantities, we also have to determine what price we would like to get for these offers. We will consider ask prices $\left(\mathrm{P}^{\text {discharge }}\right)$ and bid prices $\left(\mathrm{P}^{\text {charge }}\right)$ separately as they have different cost structures.

3.2.1. Ask (discharging) price. We construct the ask price by taking into account the cost that the carsharing operator incurs from the electricity tariff (one has to charge the battery before one can discharge it), the battery depreciation cost, the expected rental profits, plus a margin to make a profit in a "pay-as-bid" market.

$$
P_{t}^{\text {discharge }}=E T+D+\widehat{\pi_{t}}+\mu_{t} \quad \text { (Equation 2) }
$$

where ET is the industrial electricity tariff that the carsharing company is eligible for $\left(\mathrm{ET}=0.1 \frac{\$}{\mathrm{kWh}}\right.$ in the Netherlands), D is the depreciation cost $\left(\mathrm{D}=\$ 0.13 \frac{\$}{\mathrm{kWh}}\right)$, $\widehat{\pi}$ is the expected rental profits (also determined with a random forest model from Equation 1 through the day of the week, the hour of the day, and lagged dependent variables), and $\mu$ is a profit margin which is determined by optimizing it over the two month training period to maximize gross profits.

3.2.2. Bid (charging) price. We construct the bid price by taking into account the opportunity cost of not having to charge the electric vehicles at the industrial electricity tariff, the expected rental profits, plus a margin to make a profit in a "pay-as-bid" market.

$$
P_{t}^{\text {charge }}=-E T+\widehat{\pi_{t}}+\mu_{t}
$$

(Equation 3)

where ET is the industrial electricity tariff of the carsharing company, $\widehat{\pi}$ is the expected rental profit (also determined with a random forest model from Equation 1 through the day of the week, the hour of the day, and lagged dependent variables), and $\mu$ is a profit margin which is optimized over the training period for the highest payoff.

\section{Data}

We run a simulation which we calibrate with real world data on operating reserve tenders and carsharing electric vehicle usage. Our simulation comes very close to an actual field study except for the one case when the model decided to commit the storage of a car to the market, while in reality someone has rented this car which is mutually exclusive. We do account for the reduced revenues but we cannot account for the minor difference that after the rental the car in the dataset is located where the customer dropped it off after rental, while in the simulation we assume that the rental did not happen. However, this does not have an impact on the overall results because we will show that we rarely have to forego rental customers and location does not have a direct effect on the ability to offer reserve capacity on average.

\subsection{Operating reserve auction data}

The tender data, including the individual bids and market clearing quantities, for the Dutch operating reserve market are published daily by the Transmission System operator Tennet on its website. We use this data to reconstruct the merit order curve and the market clearing quantity $\mathrm{Q}^{*}$ both to absorb excess electricity and to provide additional electricity. In these merit order curves we insert additional bids and asks from the virtual power plant of electric vehicles of Car2Go. Then we clear the market according to the market clearing mechanism as described in Section 2.1. Figure 2 illustrates the average operating reserve balancing prices over the course of a day in the period June 2014 - June 2015. The grey line shows the highest average market price for charging in that period and how it changes every 15 minute interval. The black line shows the highest market clearing price that one would get for discharging an electric vehicle for every 15 minute interval. In general the market price for discharging is much higher than the price for charging because it needs to be generated. Note also the high standard deviations as indicated by the bars, which show that at times prices can be significantly higher than the average price. For simplicity we did not account for capacity prices making our results more conservative.

\subsection{Electric vehicle usage data}

Daimler provided us with data from their carsharing subsidiary Car2Go on Electric Vehicles in Amsterdam. Car2Go is a free floating carsharing business that rents electric vehicles to customers for very short amounts of time (minutes, hours). Customers can pick up any of the cars and rent them. After they have finished the rental they can to return it to any public parking spot within the defined operating area. Customers have to pay for the electric vehicles on 


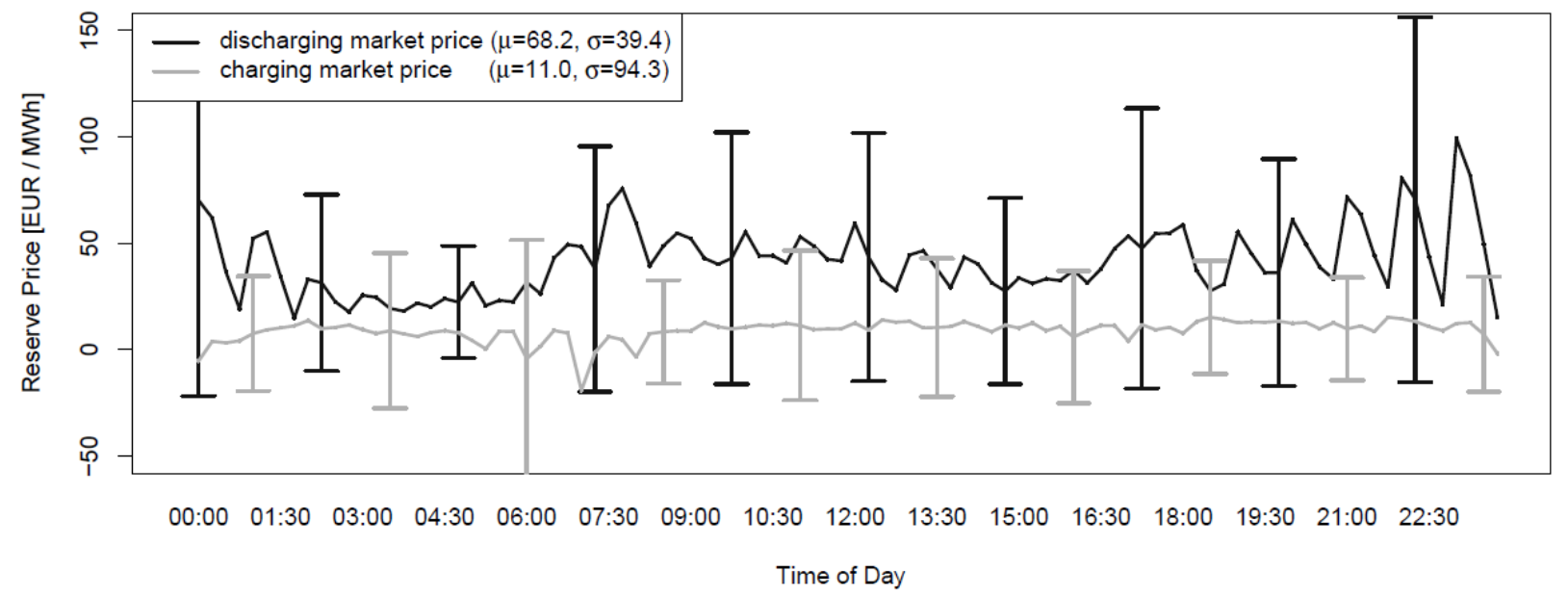

Figure 2. Average operating reserve market prices in the Netherlands 2014-2015

a minute basis plus a distance surcharge when it exceeds a $50 \mathrm{~km}$ threshold. The data that we get includes information about an ID of the electric vehicle, the state of charge in $\%$, the latitude, the longitude, the interior status (good/bad), the exterior status (good/bad), the street, the zip code, the city, and whether the car is currently charging or not. This information is available to us in real time. We download this data every 5 minutes and add a timestamp (date and time) to the data for the 14 month period March $1^{\text {st }} 2014$ - June $29^{\text {th }} 2015$. The data contains entries for parked vehicles only. However, based on the information of how long the electric vehicle is missing and the change in battery status we can infer the rental revenues based on an average fuel usage quite accurately. We calculate the rental tariff per minute times the duration plus the tariff per $\mathrm{km}$ times the distance for the rental transaction revenues.

\section{Evaluation}

In this section we are mainly concerned with the economic evaluation of using electric vehicles in virtual power plants for carsharing operators. We will illustrate how economical this is with the example of Amsterdam. First, we will analyze the decision making of our model and how this influences the profitability of Car2Go. Then we will consider seasonal patterns in carsharing and in the profitability of virtual power plants. Finally, we will put the output of the virtual power plant in perspective to the larger requirement for balancing capacity.

\subsection{Decision accuracy and profits}

The elaborate decisions that our model does for each individual 15 minute time slot over the period of a year in terms of prices and quantities to sell and buy electricity are settled in the market and executed accordingly. We have analyzed these decisions in terms of their costs and revenues for Car2Go in Amsterdam. Overall we can represent this as a classification problem. We have the choice to either commit the storage on the operating reserve market or not (equivalent to making it available for rental). Table 2 shows the confusion matrix with the aggregated profits of the choices we faced during the whole year. In the case that our model predicted that electric vehicles should not be committed to the operating reserve market it was right quite often and earned $\$ 1178,000$ gross profits from the rentals (true negatives). In many cases this decision was also wrong but this is not as problematic, because we did not do anything with idle cars, which happens currently with all idle electric vehicles (false negatives). In case that the model predicted that it would be most profitable to make a virtual power plant, while it would have been even more profitable to rent that vehicle we lost $\$ 400$ gross profits in opportunity cost compared to only the rental business model (false positives). However, the additional profits from the operating reserve market when it was also most profitable to commit to the operating reserve market make up for this by earning an additional $\$ 17.000$ gross profits annually (true positives). Overall this means that by engaging in virtual power plants on the operating reserve market, electric vehicle carsharing owners can gain an additional $\$ 16.600$ gross profits, which is a $1.4 \%$ 
Table 2. The confusion matrix shows how profitable the decisions of our model are. The added value from virtual power plants (VPP) exceeds the losses from foregone rentals by far.

\begin{tabular}{llcc} 
& & \multicolumn{2}{c}{ Predicted } \\
& & VPP & Rented \\
\multirow{2}{*}{ Actual } & VPP & $+\$ 17,000$ & - \\
& Rented & $-\$ 400$ & $\$ 1178,000$ \\
\hline
\end{tabular}

increase in gross profits. This number may appear low, but we did not take into account fixed costs of vehicles.

\subsection{Seasonal variation}

The data indicates that there is a seasonal variation in the rental data. Specifically, carsharing services are used more frequently in winter months in Amsterdam (in hotter regions it may be the summer months due to air conditioning in cars). Figure 3 shows how the gross profits develop over the year (black line). One can see clear spikes from December - March, while it is at a lower level between April - November. The erratic behavior also within the seasons may be explainable by weather differences within this period, which we leave open for future research. The profits from the virtual power plants (grey line) do not seem to follow a seasonal pattern. However, the profits with virtual power plants are consistently higher than the profits from rental only. We conclude that our model performs well and profits are evenly distributed over the seasons.

\subsection{Contribution to operating reserve market}

Our model is not only profitable for carsharing operators, but it also increases the competition on

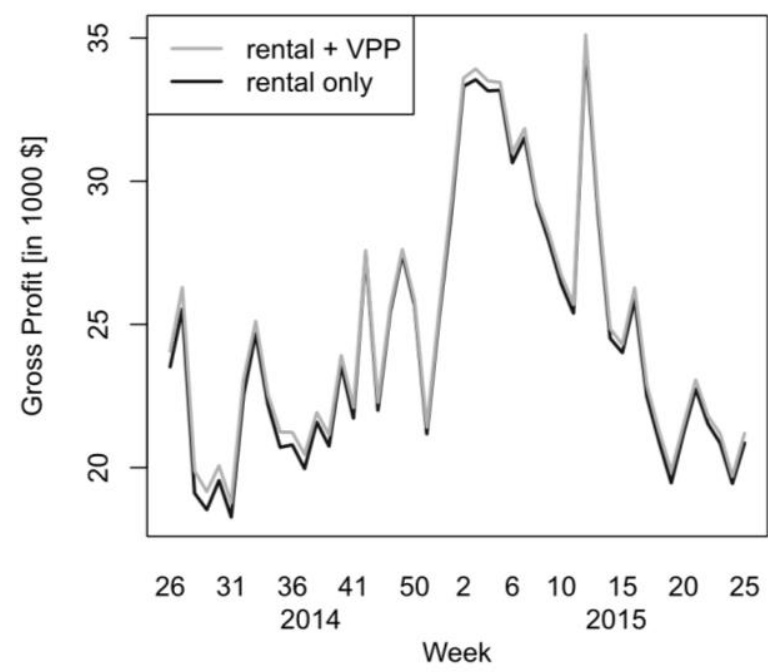

Figure 3. Shows the profit over the year. The Winter period is a driving factor for rentals in Amsterdam. The profits from offering virtual power plant power on the real-time market increases the gross profits of Car2Go consistently. operating reserve markets. Specifically, the electric vehicles offer a lucrative way for market operators to dump their excess electricity. This is especially relevant for increasing shares of renewable energy sources in the future. Figure 4 shows that the market never settled asks to discharge electricity and during the whole year not a single MWh was discharged, which is evident from the flat grey line. However, the electric vehicles contributed significantly to the market for excess electricity, which is consistent across the year. We see that mid 2014 there was a much higher need for storage from electric vehicles than in the beginning of 2015. This is due to a general decrease in the market price in this period (from $11 \$ / M W h$ to $6 \$ / M W h)$, which makes it less likely that our bids fall within the equilibrium quantities $\left(\mathrm{Q}^{*}\right)$.

\section{Conclusion}

We have shown that electric vehicle carsharing companies can enhance their profits by selling the storage of their idle electric vehicles on markets for back-up power (operating reserve markets). Compared to previous research we did not make strong assumptions on driving patterns that are known in advance and show that even with stochastic driving patterns it increases profits. With current back-up power market prices, battery depreciation cost, and charging infrastructure carsharing companies can earn most additional profits by charging their electric vehicles at times when the grid needs to get rid of excess electricity. Even though some rental profits are forgone in this way this is compensated by far from savings on cost for charging and they get an additional payment for this grid service. Our model can already be implemented with the currently available technology in Amsterdam and is ready for a practice

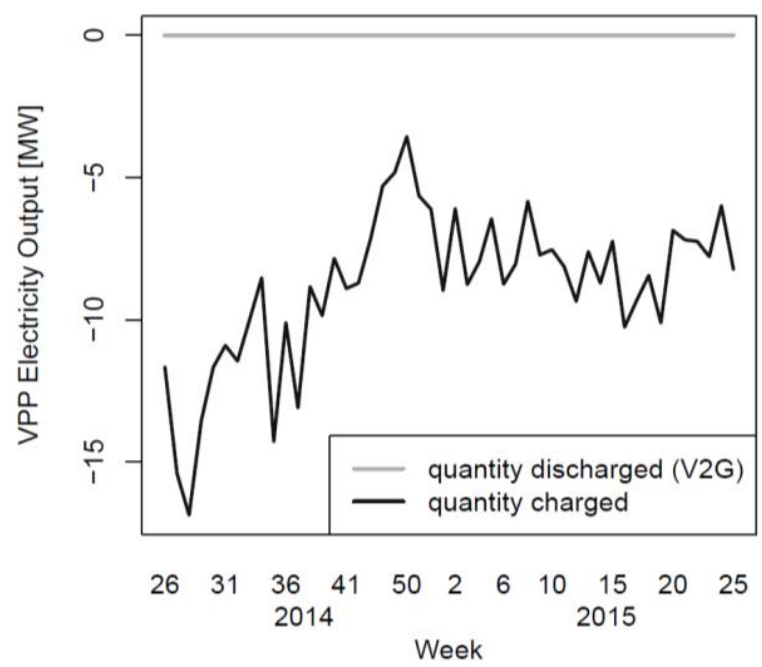

Figure 4. Shows the virtual power plant output over the year. It is striking that throughout the year much energy from the real-time market is used to charge the vehicles, while discharging vehicle-2o grid (V2G) does not occur only sporadically 3090 
trial. We find that vehicle-2-grid is less economically sound under current circumstances, which may, however, change with increasing shares of renewable energy sources and decreasing battery cost. It would also require bidirectional charging poles which are not yet widely available.

For future research we are interested in an international comparison. The Netherlands have relatively low operating reserve market prices due to a minor share of renewable energy sources of the total electricity mix. It would be interesting to compare the Dutch case to Germany or California, which have a higher share of renewable energy sources. Another way to increase the accuracy of our model is to take the limits of distribution systems into account. In contrast to conventional power plants electric vehicles are much better distributed over the city and can alleviate the burden on distribution systems and substations.

\section{References}

[1] Agricola, A., et al.. 2014. "DENA ancillary services study 2030. Security and reliability of a power supply with a high percentage of renewable energy." Technical report, German Energy Agency, Berlin, Germany.

[2] Ausubel, L. M., P. Cramton. 2010. "Virtual power plant auctions," Utility Policy (18:4), pp. 201-208.

[3] Bichler, M., A. Gupta, W. Ketter. 2010. "Designing smart markets," Information Systems Research (21:4), pp. 688-699.

[4] Brandt, T., N. DeForest, M. Stadler, D. Neumann. 2014. "Power Systems 2.0: Designing an Energy Information System for Microgrid Operation," 35th International Conference on Information Systems, Auckland, New Zealand, pp. 1-18.

[5] Fridgen, G., P. Mette, M. Thimmel. 2014. "The Value of Information Exchange in Electric Vehicle Charging," 35th International Conference on Information Systems, Auckland, New Zealand, pp. 1-20.

[6] Gallien, J., L. Wein. 2005. "A smart market for industrial procurement with capacity constraints," Management Science (51:1), pp. 76-91.

[7] Kahlen, M., W. Ketter. 2015. "Aggregating Electric Cars to Sustainable Virtual Power Plants: The Value of Flexibility in Future Electricity Markets." 29 $9^{\text {th }}$ AAAI Conference on Artificial Intelligence (AAAI-15). Austin, Texas, pp. 665-671.

[8] Kara, E., J. Macdonald, D. Black, M. Berges, G. Hug, S. Kiliccote. 2015. "Estimating the benefits of electric vehicle smart charging at non-residential locations: A datadriven approach.” Applied Energy (155), pp. 515-525.

[9] Ketter, W., M. Peters, J. Collins, A. Gupta. 2016a. "A multi-agent competitive gaming platform to address societal challenges," Management Information Systems Quarterly (40:2), pp. 447-460.

[10] Ketter, W., M. Peters, J. Collins, A. Gupta. 2016b. "Competitive Benchmarking: An IS Research Approach to Address Wicked Problems with Big Data and Analytics," Management Information Systems Quarterly (40:4), forthcoming.

[11] McCabe, K., S. Rassenti, V. Smith. 1991. "Smart computer-assisted markets," Science (254:5031), pp. 534538.

[12] Peterson, S., J. Whitacre, J. Apt. 2010. "The economics of using plug-in hybrid electric vehicle battery packs for grid storage," Journal of Power Sources (195:8), pp. 2377-2384.

[13] Porter, M. E., M. R. Kramer. 2006. "The link between competitive advantage and corporate social responsibility," Harvard Business Review (11), pp. 78-92.

[14] Pudjianto, D., C. Ramsay, G. Strbac. 2007. "Virtual power plant and system integration of distributed energy resources," Renewable Power Generation (1:1), pp. $10-16$.

[15] Quinn, Casey, Daniel Zimmerle, and Thomas H. Bradley. 2010. "The effect of communication architecture on the availability, reliability, and economics of plug-in hybrid electric vehicle-to-grid ancillary services." Journal of Power Sources (195.5) 1500-1509

[16] Reichert, S. 2010. Considerations for highly efficient bidirectional battery chargers for e-mobility. EMobility.Technologien, Infrastruktur, Maerkte. VDE-Verlag, Leipzig, 5.

[17] Schill, W. 2011. "Electric vehicles in imperfect electricity markets: The case of Germany," Energy Policy (39:10), pp. 6178-6189.

[18] Tomic, J., W. Kempton. 2007. "Using fleets of electric-drive vehicles for grid support," Journal of Power Sources (168:2), pp. 459-468.

[19] Valogianni, K., W. Ketter, J. Collins, D. Zhdanov. 2014. "Enabling sustainable smart homes: An intelligent agent approach," 35th International Conference on Information Systems, Auckland, New Zealand, pp. 1-20.

[20] Vytelingum, P., T. Voice, S. Ramchurn, A. Rogers, N. Jennings. 2011. "Theoretical and practical foundations of Large-Scale Agent-Based Micro-Storage in the smart grid," Journal of Artificial Intelligence Research (42), pp. 765-813. 